\title{
Purification of Agro Waste Saffron Using Membrane Technology-Ultrafiltration-Application to Sunscreen Cosmetic Emulsions
}

\author{
Maria Zarkogianni*, Nikolaos Nikolaidis \\ Department of Chemical Technology and Industrial Chemistry, School of Chemistry, Aristotle University, \\ Thessaloniki, Greece \\ Email: "zarkogia28@yahoo.gr
}

Received 27 June 2016; accepted 24 July 2016; published 27 July 2016

Copyright (C) 2016 by authors and Scientific Research Publishing Inc.

This work is licensed under the Creative Commons Attribution International License (CC BY).

http://creativecommons.org/licenses/by/4.0/

(c) (i) Open Access

\section{Abstract}

In this present work, ultrafiltration was applied for the purification of agro waste Greek red saffron. The agro waste saffron (before and after ultrafiltration) was used for the preparation of oilin-water emulsions. Produced emulsions were examined for their viscosity, $\mathrm{pH}$ and conductivity during time. Also surface tension values of the aqueous and oily phase of the emulsions were measured. Saffron is known for its antioxidant and anti-solar properties. Anti-solar activity of saffron was evaluated by measuring the SPF value of the emulsion. UV-Vis measurements have shown an incredible increase of the absorption of saffron after ultrafiltration. The emulsions made with the purified saffron presented a better anti-solar activity and at the same time remarkably improvement of their antioxidant and antiaging properties giving a very promising alternative to the cosmetic industry.

\section{Keywords}

Cosmetic Emulsions, SPF, Ultrafiltration, Saffron

\section{Introduction}

In the last few years, in the field of cosmetology, physical products have started to gain the interest of consumers. Because of the constantly growing use of chemicals and their harmful consequences in peoples' health, scien-

\footnotetext{
${ }^{*}$ Corresponding author.
}

How to cite this paper: Zarkogianni, M. and Nikolaidis, N. (2016) Purification of Agro Waste Saffron Using Membrane Technology-Ultrafiltration-Application to Sunscreen Cosmetic Emulsions. Open Journal of Applied Sciences, 6, 457-464. http://dx.doi.org/10.4236/ojapps.2016.67046 
tists started to look for alternative findings to surpass these problems. Thus herbals have gain attention in the cosmetology [1] [2]. Eco-friendly cosmetics appeared in the early 1900s. The biggest advantage of these cosmetics is that they are safe for humans and the environment as they do not contain any toxic chemicals, they need no animal testing and their results can be as pleasing as those achieved by commercial products.

Nowadays the rapid growth of sunscreens' marketing indicates that even though a suntan is still desired, people are nevertheless quite conscious of accompanying dangers like wrinkling, premature ageing of the skin, irregular thinning of the epidermis, solar keratosis and skin cancer occurring as a result of excessive exposure to ultraviolet (UV) radiation. Every year, more than one million people are diagnosed with skin cancer and about 10,000 die from malignant melanoma [3]. The harmful effects of solar radiation are caused predominantly by the ultraviolet (UV) region of the electromagnetic spectrum, which can be divided into three regions: UVA (320 to $400 \mathrm{~nm}$ ), UVB (290 to $320 \mathrm{~nm}$ ) and UVC (200 to $290 \mathrm{~nm}$ ). UVC radiation is filtered by the atmosphere before reaching earth. UVB radiation is not completely filtered out by the ozone layer and is responsible for the damage due to sunburn. UVA radiation reaches the deeper layers of the epidermis and dermis and provokes the premature ageing of the skin [4].

The efficacy of a sunscreen is usually expressed by the sun protection factor (SPF), which is defined, as the UV energy required to produce a minimal erythema dose (MED) on protected skin, divided by the UV energy required to produce a MED on unprotected skin. The minimal erythemal dose (MED) is defined as the lowest time interval or dosage of UV light irradiation sufficient to produce a minimal, perceptible erythema on unprotected skin. The higher the SPF, the more effective is the product in preventing sunburn

$$
\mathrm{SPF}=\frac{\text { Minimal erythema dose in sunscreen }- \text { protected skin }}{\text { Minimal erythema dose in nonsuscreen }- \text { protected skin }} \text {. }
$$

Nevertheless, it is necessary to standardize methods to determine the SPF of commercially available products. The most traditional and officially accepted method in several countries is the in vivo method of determination of SPF (FDA, United States; DIN, Germany; COLIPA, European Union; AAN, Australia). All of these are long range methods and involve 10 to 20 human volunteers of both sexes, with appropriate skin types. The in vivo method is expensive and introduces the ethical consideration of human testing. As a result of this, scientists were putting efforts to develop an in-vitro technique in assessing the efficiency of sunscreen products.

The in-vitro approaches are generally two types. 1) Measurement of absorption or the transmission of UV radiation through sunscreen product films in quartz plates or membranes; 2) methods in which the absorption characteristics of the sunscreens agents are determined based on spectrophotometric analysis. Mansur et al. developed a very simple mathematical equation to estimate the sun protection factor by in-vitro method using UV spectrophotometry [5]. The major advantage of the in vitro test is that it is a rapid, objective, cost-effective screening methodology. In vitro testing can be used as a formulation tool to identify new filters, optimize combinations of old ones, and prescreen protective formulas prior to in vivo testing in humans [6] [7].

Natural substances extracted from plants have recently been considered as potential sunscreen resources because of their ultraviolet absorption in the UV region and their antioxidant activity [8] [9].

Saffron is the aqueous extract of the dried stigmas of a flower scientifically identified as Crocus sativus L. Saffron was known by ancient nations and has remained among the world's costliest substances throughout the history [10]. It is native to Iran and Greece. It is now cultivated largely in Southern Europe, Tibet and other countries. In India it is mainly cultivated in Kashmir and Uttranchal. It is widely used as spice and as a coloring and flavoring agent in the preparation of various foods and cosmetics. The stigmas of the plant are mainly used for therapeutic purposes. Topically it is applied in the form of paste to treat skin diseases like acne [11] [12].

The chemical composition of stigmas of Crocus sativus L. has been investigated in several studies during the past two decades. Stigmas of Crocus sativus flower contain three main metabolites: 1) Crocins which are the saffron-colored compounds (unusual water-soluble carotenoids due to their high glycosyl contents); 2) Picrocrocins which are the main substances responsible for saffron's bitter taste and 3) Safranal which is the volatile oil responsible for the typical saffron aroma. In addition to crocin and picrocrocin, the major compounds in saffron, anthocyanins, flavonoids, vitamins, amino acids, proteins, starch, mineral matter, gums and other chemical compounds have been found in saffron. Figure 1 illustrates the structure of the most important component of saffron [13] [14].

Many techniques have been developed for the purification of the industrial effluents. Ultrafiltration technology is one of the newest technologies applied for the treatment of industrial and hazardous effluents aiming at the 


\section{Crocetin}

\section{Safranal}

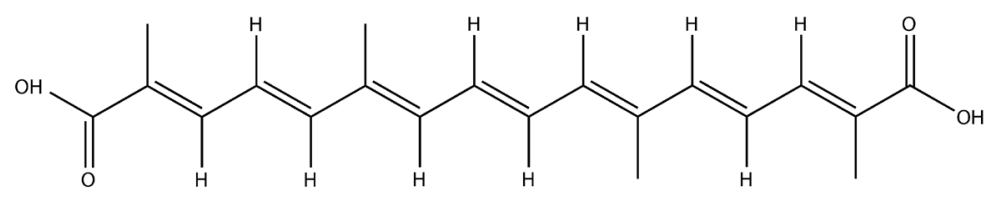<smiles>CC1=C(C=O)C(C)(C)CC=C1</smiles><smiles>CC1=C(C(=O)OC(Cl)(Cl)Cl)C(C)(C)C[C@H](C[C@H]2O[C@H](CO)[C@@H](O)[C@H](O)[C@H]2O)C1</smiles>

Figure 1. Chemical composition of the most active constituents of saffron.

elimination of toxic pollutants in the discharged effluents. In this present work ultrafiltration was applied for the purification of agro waste Greek red saffron (Crocus sativus, Kozani, Greece) [15]. Ultrafiltration allows the production of highly concentrated, purified dyes.

Three oil-in-water emulsions were prepared, one without saffron (base), one with $0.1 \%$ w/v aqueous extract of agro waste saffron (Saffron) and one with $0.1 \% \mathrm{w} / \mathrm{v}$ aqueous extract of ultrafiltrated agro waste saffron (UFSaffron). Olive oil was used for the preparation of the oily phase of the emulsion. The selected emulsifier was a combination of polysorbate 60 (polyoxyethylene sorbitan monostearate) and cetearyl alcohol. The SPF values of the oil-in-water emulsions containing saffron was determined by an in vitro method. Additionally $\mathrm{pH}$, surface tension, conductivity and viscosity measurements were made to the emulsion during time $(1,7,15,30,60,90$ days). Evaluation of the results are presented and discussed in detail.

\section{Materials and Methods}

\subsection{Materials}

Raw saffron waste was supplied from Crocos farmers from Kozani area. The saffron waste was what was left after selecting the premium saffron quality. This raw saffron waste is considered to be of non-commercial value. Tetrasodium EDTA, xanthan gum, cetearyl alcohol and polysorbate 60 (Polyoxyethylene sorbitan monostearate) were purchased from NOVITA Group (Marise Perfumes). Glycerin was obtained from Emery Oleochemicals. Cetyl alcohol was obtained from BASF. Stearic acid was purchased from NAPOLEO (Natural Oleochemicals). Caprylic/Capric triglyceride was obtained from CRODA. Butyrospermum Parkii (Shea) Butter was obtained 
from A. \& A. Fratelli Paradi s.p.a. and 2-phenoxyethanol from Sharon Laboratories. Greek extra virgin Olive oil was obtained by "MINERVA" and ethanol (pro analysi) from MERCK. The above compounds were used to the preparation of the emulsions (Table 1 ).

\subsection{Apparatus}

A Shimadzu UV-2101 spectrophotometer equipped with $1 \mathrm{~cm}$ quartz cell was used. $\mathrm{pH}$ measurements were made using a WTW pH535 microprocessor. Surface Tension measurements were taken with the Wilhelmy plate technique using a KSV Sigma 70 tensionmeter. The viscosity values were taken by using the viscometer Visco Star Plus. The overhand mixer used was obtained from IKA-WERCK (RW 14H). The ultrasonic processor used was UP 100H from Hielscher and the conductivity measurements were taken by a CRISON Basic 30 conductivity meter.

\subsection{Extraction of Saffron}

The ground agro waste saffron (Crocus sativus L.) was placed into a beaker with de-ionised water in a proportion of $2 \% \mathrm{w} / \mathrm{v}$. The material was warmed up for almost 3 hours at $80^{\circ} \mathrm{C}-90^{\circ} \mathrm{C}$ with simultaneous stirring and then was kept until next morning in room temperature and in dark in order to have a complete extraction. The aqueous phase was selected and dried until the dry ground saffron was obtained [16].

\subsection{Ultrafiltration Process}

A laboratory ultra-filtration unit equipped with tubular membrane supplied by PCI Membranes (UK) was used throughout our work. The membrane used for the ultra-filtration process was the ES404, a polyethersulphone type membrane supplied by PCI Membranes (UK). The ultrafiltration process for 1.5L of a liquid extract (2\%) of agro waste saffron was carried out at $\sim 30^{\circ} \mathrm{C}$, pressure 15 bar and with a flow rate $\sim 20 \mathrm{ml} / \mathrm{min}$. One volume of water $(1.5 \mathrm{~L})$ was added at the stage of diafiltration and the process continued till the concentration of the initial volume at $\sim 750 \mathrm{ml}$. The permeate was dried and purified saffron was received.

\subsection{Emulsification Process}

Emulsification was implemented by mixing the water phase with the oily phase (Table 1) using an impeller rotating at the central axis of a glass vessel. Emulsions were prepared in the above glass vessel as follows. Initially the aqueous phase was heated to $70^{\circ} \mathrm{C}$. The appropriate amount of the oily phase was heated separately to $70^{\circ} \mathrm{C}$ until the material was melt. Emulsification started by adding the hot oily phase into the aqueous phase under

Table 1. Emulsion constituents with their \% content.

\begin{tabular}{cc}
\hline Aqueous Phase (70\%) & \\
\hline Constituents & $67 \%$ \\
\hline Water or Aqueous Extract of Saffron & $2.3 \%$ \\
Glycerin & $0.2 \%$ \\
Tetrasodium EDTA & $0.5 \%$ \\
\hline Xanthan Gum & \\
\hline Oily Phase (30\%) & \\
\hline Constituents & $13 \%$ \\
\hline Olive Oil & $4 \%$ \\
\hline Polysorbate 60 + Cetearyl Alcohol (1:1) & $2 \%$ \\
Cetyl Alcohol & $1 \%$ \\
Stearic Acid & $7 \%$ \\
Triglyceride & $2 \%$ \\
Shea Butter & $1 \%$ \\
\hline Phenoxyethanol & \\
\hline
\end{tabular}


stirring. At that moment heat supply was turned off and agitation was set at $700 \mathrm{rpm}$ and continued for almost 2 hours until the emulsion to cool down to room temperature. Phenoxyethanol was added at the emulsion at about $50^{\circ} \mathrm{C}$. In Table 1 , the emulsion constituents with their $\%$ content are given.

\subsection{Sample Preparation and Determination of SPF}

All samples $(1 \mathrm{~g})$ were weighed, transferred to a $100 \mathrm{~mL}$ volumetric flask, diluted to volume with ethanol, mixed for $15 \mathrm{~min}$ and then filtered through Whatman filters. A $5.0 \mathrm{~mL}$ sample was transferred to a $25 \mathrm{~mL}$ volumetric flask and diluted to volume with ethanol. The measurements were made either at the solutions after the first dilution to $100 \mathrm{~mL}$ or after the second dilution to $25 \mathrm{~mL}$ because of the small proportion of saffron that was chosen to be used. The absorption values were obtained in the range of 290 to $320 \mathrm{~nm}$ (every $5 \mathrm{~nm}$ ). Each measurement was conducted three times and the value given is the mean value at each point. Mansur equation was used to determine the SPF values of the formulations. Mansur et al. (1986) developed a very simple mathematical equation, which in conjunction with substitutes the in vitro method proposed by Sayre et al. (1979), UV spectrophotometry. The introduced equation is as follows:

$$
S P F=C F \times \sum_{320}^{290} E E_{(\lambda)} I_{(\lambda)} a b s_{(\lambda)}
$$

where $C F=10$ (Correction Factor), $E E_{(\lambda)}=$ Erythemogenic Effect of radiation at wavelength $\lambda, I_{(\lambda)}=$ Intensity of solar light at wavelength $\lambda$, and $\operatorname{abs}_{(\lambda)}=$ Absorbance of wavelength $\lambda$ by a solution of the preparation. It was determined so that a standard sunscreen formulation containing $8 \%$ homosalate presented an SPF value of 4 , determined by UV spectrophotometry [Mansur et al., 1986]. The values for the term " $E E \times I$ " are constants, which were determined by Sayre et al. (1979), and are shown in Table 2 [17].

\section{7. pH, Conductivity, Viscosity and Surface Tension Measurements}

$\mathrm{pH}$ and conductivity measurements were made by dipping the $\mathrm{pH}$ or the conductivity sensor into the emulsion. Viscosity measurements were made by dipping the spindle R3 of the viscometer into the emulsion. The surface tension measurements were taken with the Wilhelmy plate technique. The platinum plate was partially immersed into the oil or the aqueous phase, where it remained to fixed position during the course of the experiment. Thus, the surface tension decreased as a function of time. When the surface tension was stabilized then the experiment was stopped. All measurements were made at $25^{\circ} \mathrm{C} \pm 0.1^{\circ} \mathrm{C}$.

\section{Results and Discussion}

\subsection{Ultrafiltration}

In Table 3, the effectiveness of the UF membrane to purify the agro waste saffron is clearly shown. $0.1 \% \mathrm{w} / \mathrm{v}$

Table 2. Normalized product function used in the calculation of SPF.

\begin{tabular}{cc}
\hline Wavelength $(\lambda \mathrm{nm})$ & EE $\times$ I (normalized) \\
\hline 290 & 0.0150 \\
295 & 0.0817 \\
300 & 0.2874 \\
305 & 0.3278 \\
310 & 0.1864 \\
315 & 0.0839 \\
320 & 0.0180 \\
Total & 1 \\
\hline
\end{tabular}

Table 3. UV-Vis measurements of agro waste saffron before and after ultrafiltration.

\begin{tabular}{ccc}
\hline Sample & $\lambda \max (\mathrm{nm})$ & Absorption \\
\hline Agro waste saffron & 438 & 0.708 \\
Ultrafiltrated agro waste saffron & 438 & 2.607 \\
\hline
\end{tabular}


aqueous solutions of agro waste saffron before and after ultrafiltration had been measured. The ultrafiltrated saffron absorption is more than three times the absorption of the agro waste saffron. The quality improvement resulted by this membrane technology opens new areas of application of the ultra-filtrated agro waste saffron.

\subsection{SPF Determination}

In this study three emulsions with and without saffron were evaluated by UV spectrophotometry using Mansur mathematical equation. The SPF values of the emulsions with $0.1 \% \mathrm{w} / \mathrm{v}$ aqueous solution of agro waste saffron before and after ultrafiltration and the emulsion containing no saffron were measured. The measurements were conducted after the first dilution with ethanol $(100 \mathrm{~mL}$, a) and after the second dilution with ethanol $(25 \mathrm{~mL}, \mathrm{~b})$. Figure 2(a) \& Figure 2(b) show the SPFs of emulsions. It was concluded from this that the SPF of saffron emulsion in all cases were significantly higher than that of the base emulsion and that emulsions containing ultrafiltrated saffron showed higher SPF values than the others apparently due to the three times higher absorbance value achieved by ultrafiltration. These results show that saffron can act as a very good antisolar agent against the harmful UV radiation.

\section{3. pH, Conductivity, Viscosity and Surface Tension Measurements}

The measurements of $\mathrm{pH}$, conductivity and viscosity of the emulsions during time are shown in Figure 3 . All the emulsions show remarkable $\mathrm{pH}$ and viscosity stability during time. The conductivity in all cases shows slight decrease during time. The surface tension values of the aqueous and oily phases are shown in Table 4 and are in accordance with the literature data [18] [19].

\section{Conclusion}

The results of this present work indicate that saffron can be used as a natural UV-absorbing agent in sunscreen

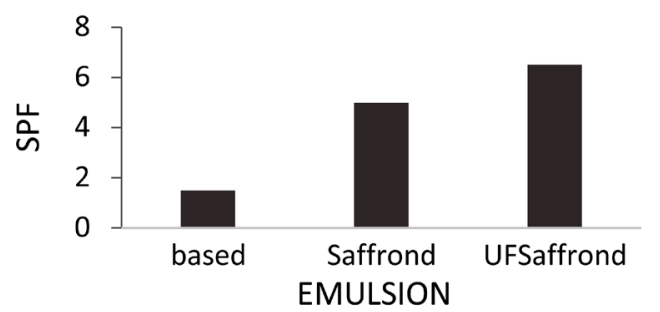

(a)

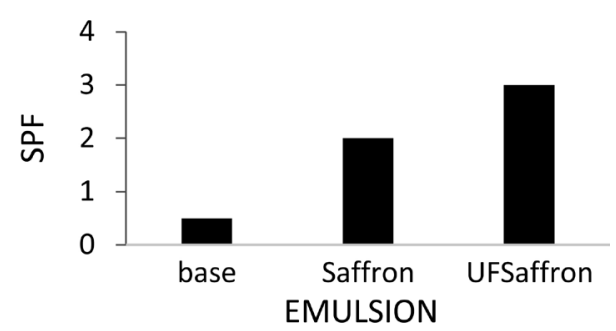

(b)

Figure 2. SPF values of the emulsions: (a) after the first dilution and (b) after the second dilution.
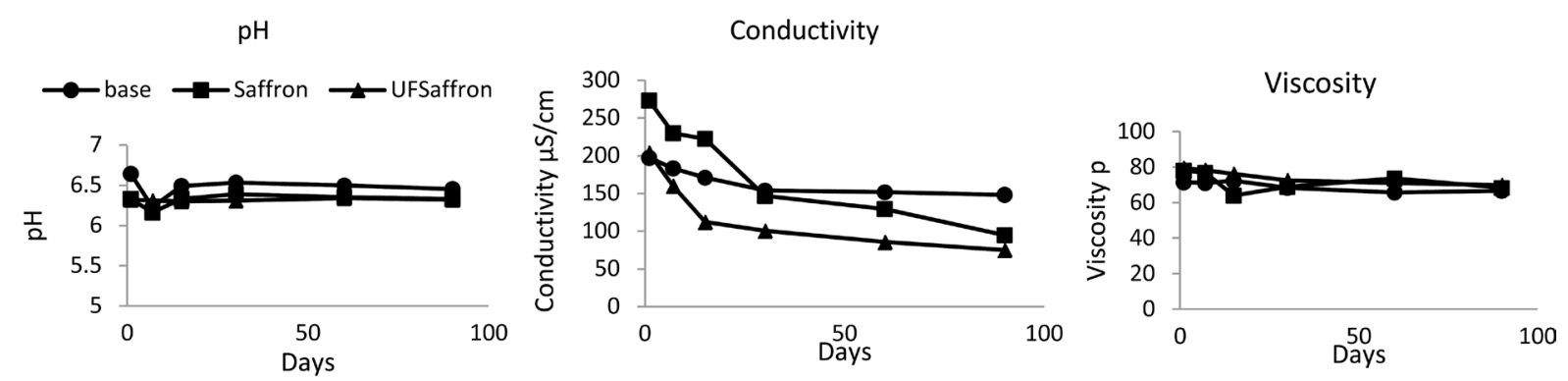

Figure 3. pH, conductivity and viscosity measurements of the emulsions during time.

Table 4. Surface tensions of oily and aqueous phases.

\begin{tabular}{ccc}
\hline Phase & Temperature $\left({ }^{\circ} \mathrm{C}\right)$ & Surface tension $(\mathrm{mN} / \mathrm{m})$ \\
\hline Olive oil & $25 \pm 0.1$ & 31 \\
Water & $25 \pm 0.1$ & 71.6 \\
Aqueous solution $0.1 \%$ saffron & $25 \pm 0.1$ & 48.6 \\
\hline
\end{tabular}


cosmetic products and the ultrafiltrated saffron shows a better SPF value. The ultrafiltration of agro waste saffron leads to a highly purified product meaning that the agro waste saffron, a waste till now, can be a valued constituent of sunscreen products. Viscosity, $\mathrm{pH}$ and conductivity measurements indicated that the emulsions made in all cases are significant stable during time. The above results in combination with all the significant properties of saffron known from the literature are very promising in the direction of an additional use of saffron in cosmetics and especially in sunscreen products.

\section{Acknowledgements}

This study was financially supported by "IKY FELLOWSHIPS OF EXCELLENCE FOR POSTGRADUATE STUDIES IN GREECE-SIEMENS PROGRAM”.

\section{References}

[1] Aburjai, T. and Natsheh, F.M. (2003) Plants Used in Cosmetics. Phytotherapy Research, 17, 987-1000. http://dx.doi.org/10.1002/ptr.1363

[2] Wang, K.H., Lin, R.D., Hsu, F.L., Huang, Y.H., Chang, H.C., Huang, C.Y. and Lee, M.H. (2006) Cosmetic Applications of Selected Traditional Chinese Herbal Medicines. Journal of Ethnopharmacology, 106, 353-359. http://dx.doi.org/10.1016/j.jep.2006.01.010

[3] Golmohammadzadeh, S., Jaafari, M.R. and Hosseinzadeh, H. (2010) Does Saffron Have Antisolar and Moisturizing Effects? Iranian Journal of Pharmaceutical Research, 9, 133-140.

[4] Dutra, E.-A., Oliveira, D.-A., Kedor Hackmann, E.-R. and Santoro, M.I. (2004) Determination of Sun Protection Factor (SPF) of Sunscreens by Ultraviolet Spectrophotometry. Brazilian Journal of Pharmaceutical Sciences, 40, 381-385. http://dx.doi.org/10.1590/s1516-93322004000300014

[5] Mansur, J.S., Breder, M.N.R., Mansur, M.C.A. and Azulay, R.D. (1986) Determinação Do Fator De Proteção Solar Por Espectrofotometria. An Bras Dermatol Rio De Janeiro, 61, 121-124.

[6] Mbanga, L., Mulenga, M., Mpiana, P.T., Bokolo, K., Mumbwa, M. and Mvingu, K. (2014) Determination of Sun Protection Factor (SPF) of Some Body Creams and Lotions Marketed in Kinshasa by Ultraviolet Spectrophotometry. International Journal of Advanced Research in Chemical Science, 1, 7-13.

[7] Sudhahar, V. and Balasubramanian, V. (2013) Sun Production Factor (SPF) Determination of Marketed Sunscreen Formulation by In-Vitro Method Using UV-VIS Spectrophotometer. Archives of Applied Science Research, 5, 119122.

[8] Tabrizi, S., Mortazavi, S.A. and Kamalinejad, M. (2003) An in Vitro Evaluation of Various Rosa damascena Flower Extracts as a Natural Antisolar Agent. International Journal of Cosmetic Science, 25, 259-265. http://dx.doi.org/10.1111/j.1467-2494.2003.00189.x

[9] Khazaeli, P. and Mehrabani, M. (2008) Screening of Sun Protective Activity of the Ethyl Acetate Extracts of Some Medicinal Plants. Iran. J. Pharmaceut., 7, 5-9.

[10] Mousavi, S.Z. and Bathaie, S.Z. (2011) Historical Uses of Saffron: Identifying Potential New Avenues for Modern Research. Avicenna Journal of Phytomedicine, 1, 57-66.

[11] Bhargava V.K. (2011) Medicinal Uses and Pharmacological Properties of Crocus sativus Linn (Saffron). International Journal of Pharmacy and Pharmaceutical Sciences, 3, 21-26.

[12] Sampathu, S.R, Shivashankar, S., Lewis, Y.S. and Wood, A.B. (1984) Saffron (Crocus sativus Linn.) —Cultivation, Processing, Chemistry and Standardization. C R C Critical Reviews in Food Science and Nutrition, 20, 123-157. http://dx.doi.org/10.1080/10408398409527386

[13] Mashmoul, M., Azlan, A., Khaza'ai, H. and Yusof, B.N.M., Noor S.M. (2013) Saffron: A Natural Potent Antioxidant as a Promising Anti-Obesity Drug. Antioxidants, 2, 293-308. http://dx.doi.org/10.3390/antiox2040293

[14] Tsatsaroni, E.G. and Eleftheriadis, I.C. (1994) The Colour and Fastness of Natural Saffron. Journal of the Society of Dyers and Colourists, 110, 313-315. http://dx.doi.org/10.1111/j.1478-4408.1994.tb01666.x

[15] Simonic, M. (2009) Efficiency of Ultra-Filtration for the Pre-Treatment of Dye-Bath Effluents. Desalination, 246, 328-334.

[16] Tsimidou, M. and Tsatsaroni, E. (1993) Stability of Saffron Pigments in Aqueous Extracts. Journal of Food Science, 58, 1073-1075. http://dx.doi.org/10.1111/j.1365-2621.1993.tb06116.x

[17] Sayre, R.M., Agin, P.P., Levee, G.I. and Marlowe, E. (1979) Comparison of in Vivo and in Vitro Testing of Sunscreening Formulas. Photochemistry and Photobiology, 29, 559-566. http://dx.doi.org/10.1111/j.1751-1097.1979.tb07090.x 
[18] Pallas, N.R. and Harrison, Y. (1990) An Automated Drop Shape Apparatus and the Surface Tension of Pure Water. Colloids and Surfaces, 43,169-194. http://dx.doi.org/10.1016/0166-6622(90)80287-E

[19] Varka, E.-M., Tsatsaroni, E., Xristoforidou, N. and Darda, A-M. (2012) Stability Study of O/W Cosmetic Emulsions Using Rosmarinus officinalis and Calendula officinalis Extract. Open Journal of Applied Sciences, 2, 139-145.

http://dx.doi.org/10.4236/ojapps.2012.23020

\section{Submit or recommend next manuscript to SCIRP and we will provide best service for you:}

Accepting pre-submission inquiries through Email, Facebook, LinkedIn, Twitter, etc.

A wide selection of journals (inclusive of 9 subjects, more than 200 journals)

Providing 24-hour high-quality service

User-friendly online submission system

Fair and swift peer-review system

Efficient typesetting and proofreading procedure

Display of the result of downloads and visits, as well as the number of cited articles

Maximum dissemination of your research work

Submit your manuscript at: http://papersubmission.scirp.org/ 